\title{
RECORD OF A GIANT EGG MASS OF MELO DUCALE (LAMARCK) FROM THE ARAFURA SEA
}

$\operatorname{AUTHOR}(\mathrm{S})$ :

Tokioka, Takasi

\section{CITATION:}

Tokioka, Takasi. RECORD OF A GIANT EGG MASS OF MELO DUCALE (LAMARCK) FROM THE ARAFURA SEA. PUBLICATIONS OF THE SETO MARINE BIOLOGICAL LABORATORY 1962, 10(1): $21-26$

\section{ISSUE DATE:}

1962-07-30

URL:

http://hdl.handle.net/2433/175301

RIGHT: 


\title{
RECORD OF A GIANT EGG MASS OF MELO DUCALE (LAMARCK) FROM THE ARAFURA SEA ${ }^{13}$
}

\author{
TAKASI TOKIOKA
}

Seto Marine Biological Laboratory

With Plate IV and 2 Text-figures

In 1954, Mr. Mamoru Hayami, the chief diver of the first Miyo-Maru, offered me so kindly a giant gastropod egg mass together with a group of egg capsules of Syrinx proboscidiferus (LAMARK), both were collected in the pearl oyster ground of the Arafura Sea during divings for collecting silvery lipped pearl oysters.

The egg mass is roughly cylindrical in shape, about $250 \mathrm{~mm}$ in length and with a $50 \mathrm{~mm}$ diameter at one end and a $85 \mathrm{~mm}$ diameter at the other end. The mass consists of about 140 strawberry-shaped capsules arranged spirally in two directions (Pl. IV, Fig. $1 a$ ). About five capsules are found on a section near the thinner end, while up to ten capsules are counted on a plane sectioned near the opposite thicker end. Capsules are each placed with the bluntly pointed end inwards, while the obtuse side is swollen roundly, faced the exterior, and covered with the gelatinous coat connecting the capsule with four adjoining ones. Thus, the egg mass contains a spacious axial lacuna which is opened to the exterior through a number of windows made between the crossed gelatinous bands. The capsule is up to $30 \mathrm{~mm}$ in length and $20 \mathrm{~mm}$ in width at the level of the basal one-third, and its section is somewhat elliptical rather than circular, with the longer axis on the transverse plane of the egg mass. The gelatinous coat is fournished with several ridges converging roughly on the middle of the proximal side of the capsule and extends to the range from the basal one-third to the middle of the capsule. The capsule wall is rather thin, about $0.5 \mathrm{~mm}$ in thickness, translucent, and faintly milky-white like the gelatinous coat. The humour filling the capsule is purplish brown; only a single embryo is found in each capsule, it is in an earlier stage of development and carrying a small shell completely softened in formalin.

The embryos examined are evidently in the veliger stage as shown in fig. $2 \mathrm{e}$; the height is about $3.3 \mathrm{~mm}$ and the maximum width is $3.4 \mathrm{~mm}$ in an examined

1) Contributions from Seto Marine Biological Laboratory, No. 380.

Publ. Seto Mar. Biol. Lab., X (1), 1962. (Article 2) 


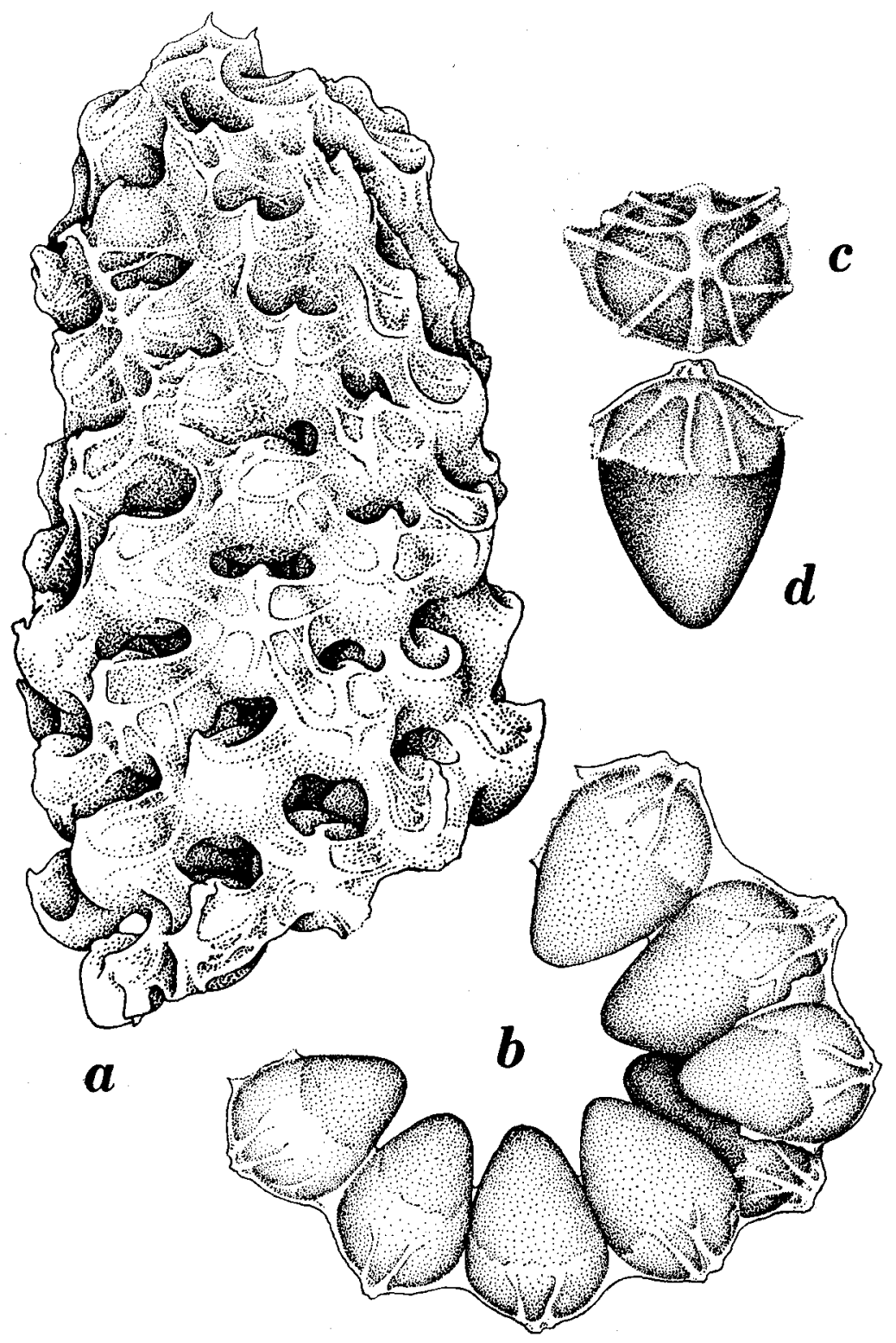

Text-fig. 1. Egg mass of Melo ducale (LAMARCK) from the Arafura Sea. $a \cdots \mathrm{A}$ part of egg mass, $b \cdots A$ part of the section through the egg mass, $c \cdots$ Top view of capsule, $d$...Side view of capsule; $\times 2 / 3$. 

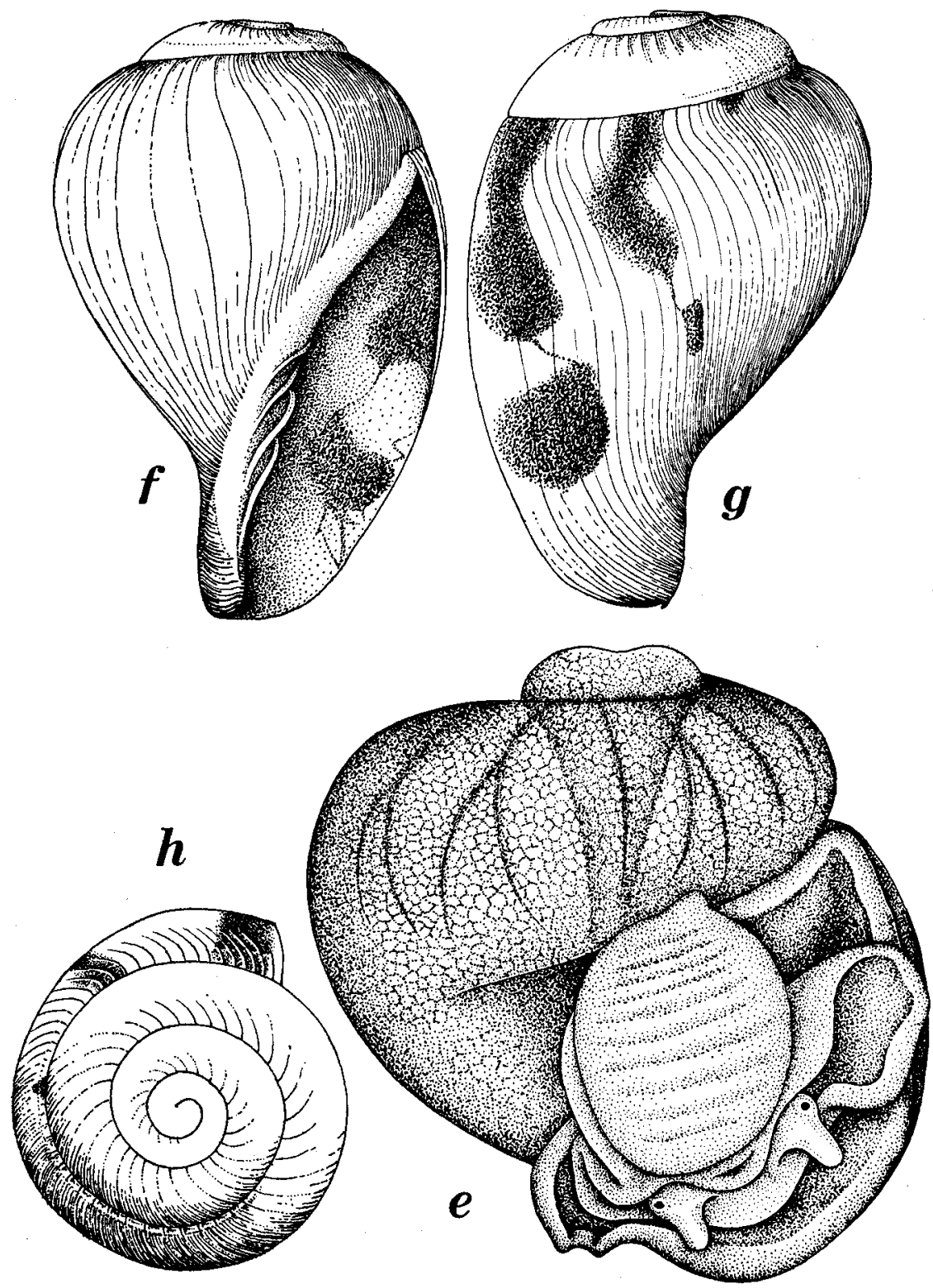

Text-fig. 2. Melo ducale (LAMARCK). $\quad$-..Embryo from the egg mass, front side, $\times 23$; $f \cdots$ Larval shell, front side, $\times 3.3 ; g \cdots$ Back side of the same shell, $\times 3.3$; $h \cdots$ Top view of the same shell, $\times 3.3$. 
specimen. The shell coils only two times; the spire is small, and the body whorl is very large and not narrowed anteriorly. A pair of tentacles are seen in front of the pedal disc, each with a sensory pigment fleck at the outer base. The mantle beneath the softened shell looks finely reticulated and has about a dozen longitudinal striations which might correspond to growth lines or longitudinal crests found on the larval shell.

As the egg mass is very large, this must belong to some huge shell other than Syrinx. And there are three species of giant Melo in the Arafura Sea. Prof. G. Thorson expressed his opinion when he examined the egg mass in the autumn of 1961 that this might belong to Melo. But, unfortunately the contents of the egg mass are in very earlier stages of development and consequently the egg mass has not been identified for a certainty.

Recently, Mr. Yohiti Sibata, an old conchologist famous in this district and at the same time the person contributed much for establishing our laboratory, offered me a small piece of the dried egg mass which was brought him from the Arafura Sea. Although this was dried completely, I could identify it easily with my egg mass. The piece contains about ten larval shells one in each capsule. The shell is roughly fig-shaped, up to $22 \mathrm{~mm}$ in height and $14 \mathrm{~mm}$ in the maximum breadth. It coils 4 to $4-1 / 2$ times, the spire is very low and the body whorl is very large. The first one and a quarter or a half whorls are on a nearly even plane. The penultimate whorl is about a quarter as high as the body whorl at the level of the shell aperture. The body whorl is narrowed anteriorly in the distal one-third ; the outer lip of the aperture is, however, curving evenly. The posterior end of the aperture is narrowed, while the anterior end is rather wide, the outer lip reaching the columellar end nearly perpendicularly. Callus is defined disitnctly and furnished with four columellar folds in the anterior half. A number of faint longitudinal crests are found along the suture; they are short, reaching to one-third across the surface of the penultimate and the preceding whorls. The shell is of a moderate thickness, faintly yellowish brown and marked with a few dark brownish patterns on the body whorl near the aperture; growth lines are distinct on the body whorl. Each colour pattern consists of a posterior elongate curved patch beginning at the suture and an anterior one. Usually one to two patterns are seen, besides a rudimentary posterior patch on some shells. No signs of spines are found on any examined shells.

The existence of so distinct columellar folds and the appearance of colour patterns seem to place the present larval shells near Melo ducale (LAMARCK), the species most commonly collected in the pearl oyster ground in the Arafura Sea. The adult shells of $M$. ducale has two colour bands on the body whorl, both far apart from the suture between the body and penultimate whorls. Fortunately, by courtesy of Mrs. S. SaIKa I colud have a chance to examine a series of young shells of this species and confirm that the posterior colour patch of larval shell, 
mentioned above, does not appear on later whorls and the series of the anterior patches becomes to be the posterior colour band on the body whorl of adult shells.

However, it is very possible that other species of Melo, M. amphora SolAnder and $M$. melo SolANDER, especially the former, lay very similar egg masses, and therefore, there remains still a slight doubt about the identification of the present egg mass. Lastly, before closing this note $I$ want to express my hearty thanks to Mr. HAYAmi for his kindness in bringing me the present precious specimen. 
EXPLANATION OF PLATE IV

A-Entire egg mass, $\times 0.57$

B-Narrower end of the same egg mass, $\times 0.64$ 


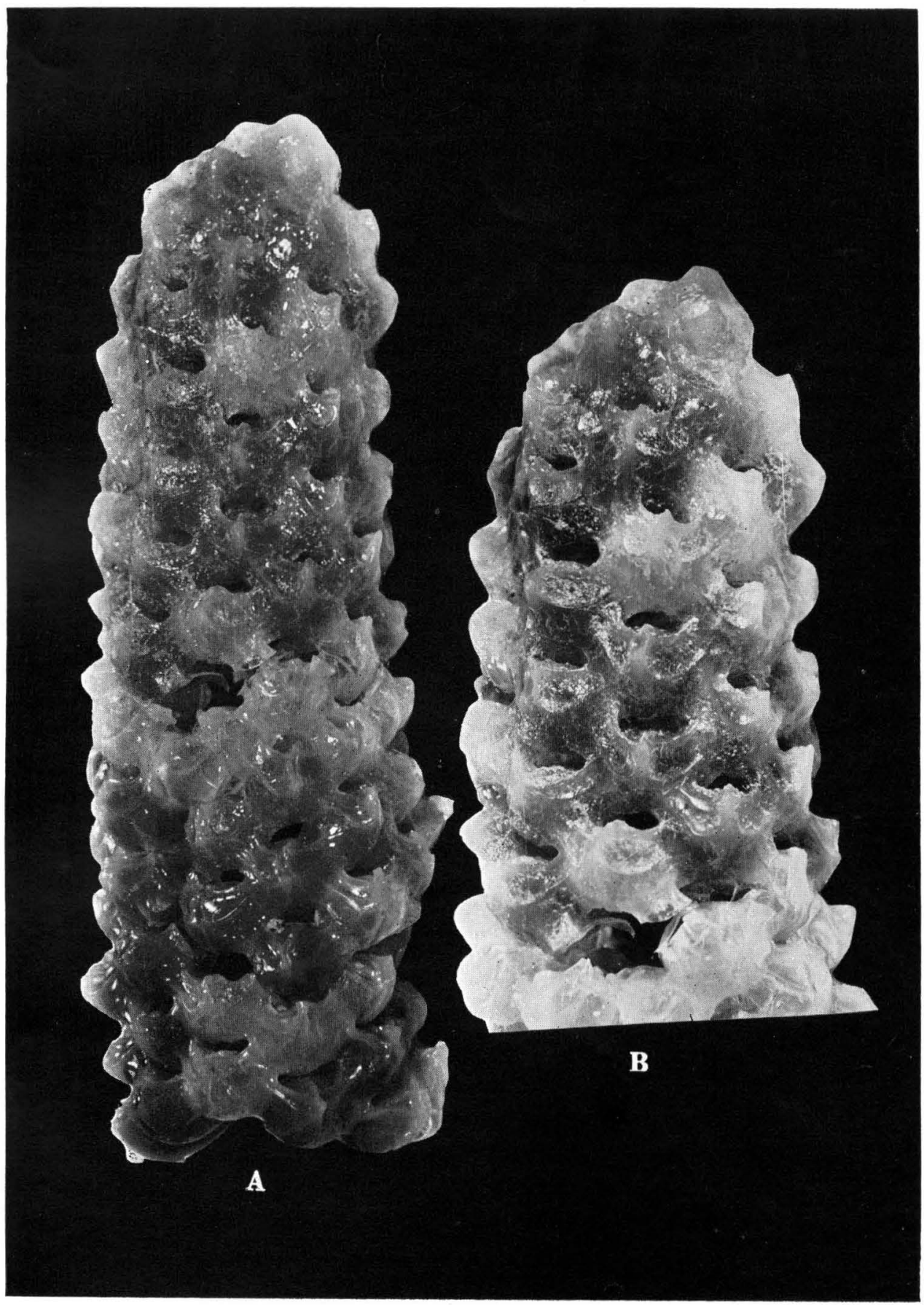

T. Tokioka: Giant Egg Mass of Melo ducale. (E. Harada photo.) 